\title{
SFMEA: Análise do Efeito e Modo da Falha em Serviços - aplicando técnicas de prevenção na melhoria de serviços
}

\author{
Roberto Giliol Rotondaro \\ Departamento de Engenharia de Produção, \\ Professor Doutor da Escola Politécnica da USP, \\ E-mail: rotondar@cwaynet.com.br
}

\begin{abstract}
Resumo
De acordo com a definição de serviços, uma das características é a proximidade com o cliente durante o processo de elaboração e entrega do serviço, por isso, se alguma coisa der errada, isto acontecerá na sua frente.

Este artigo mostra como, a partir dos conceitos da técnica FMEA, é desenvolvida uma ferramenta de prevenção, a SFMEA, que é adequada para prevenir a ocorrência de falhas durante a produção dos serviços, de modo que estes sempre atendam às expectativas dos clientes. Um grupo de pessoas envolvidas com a tarefa desenha o fluxo do serviço identificando os momentos da verdade, aqueles momentos em que o cliente entra em contato com a organização prestadora do serviço. Estes pontos serão a base para a aplicação da técnica de SFMEA, de modo a eliminar a possibilidade de falhas durante a entrega do serviço. São apresentados dois exemplos de aplicação da ferramenta, de modo a comprovar a sua eficácia.
\end{abstract}

Palavras-chave

Serviços, Prevenção, Qualidade.

\section{SFMEA: Service Failure Mode and Effect Analysis}

\begin{abstract}
According to Service definition, the customer is frequently present during the processes and delivery of the service. If something goes wrong it will happen in front of the customer.

This article shows that the use of SFMEA as a prevention tool in the service's business is a very powerful technique. A group of employees were trained in prevention tools, designed the process map, found the critical points and applied the SFMEA method in order do prevent any failure during services operation. The first results indicated that all the actions implemented were really effective and SFMEA is a good tool for preventing errors.
\end{abstract}

Key words

Service, Prevention, Quality. 


\section{INTRODUĈ̣̃O}

Dentre as várias características da atividade de prestação de serviços, três são muito críticas para a qualidade percebida pelo cliente (PARASURAMAM et al., 1990):

- A intangibilidade: O serviço é normalmente percebido de maneira subjetiva, sendo que o seu resultado está sempre relacionado com os sentimentos do cliente.

- A participação do cliente no processo: A presença do cliente no processo de produção do serviço introduz um elemento não controlado pelo prestador do serviço e ainda acrescenta a necessidade de o cliente ficar satisfeito com a forma como o serviço é prestado.

- A produção e o consumo são, em muitos tipos de serviços, simultâneos: Não há a possibilidade de controlar a qualidade antes do consumo do serviço.

Considerando estas características, o provedor do serviço deve procurar desenvolver um processo que seja à prova de erros. Simplesmente o desafio é conseguir zero defeitos.

Como a inspeção prévia do serviço não pode ser efetuada, e como as ações corretivas apenas são aplicadas após o erro ter sido cometido e o cliente estar insatisfeito, o provedor deve utilizar ferramentas de prevenção que estudem os pontos críticos onde podem ocorrer falhas no processo e fazer previamente as mudanças necessárias, de forma a eliminar as possíveis causas de erros. A indústria automobilística já utiliza há bastante tempo e com sucesso o FAILURE MODE AND EFFECT ANALYSIS (FMEA) como forma de prevenir a ocorrência de defeitos de seus processos e projetos. A QS9000 requer a utilização de FMEA como parte obrigatória para a aprovação de uma peça nova (PPAP, 2000).

Este artigo apresenta a utilização da metodologia "SFMEA" como uma ferramenta de prevenção para a área de Serviços, para os momentos em que o cliente está presente ao processo de prestação do serviço, e a produção e o consumo são simultâneos. É feita uma adaptação que incorpora ao FMEA tradicional elementos que cobrem os aspectos específicos da prestação de serviços. Para as atividades das operações de serviço onde o cliente não está presente, o FMEA tradicional é uma ótima ferramenta de ação preventiva.

\section{O FLUXO DE PROCESSO DE SERVIC̣OS}

Normann (1993) afirma que a qualidade experimentada pelo cliente é criada no que chamou de "Momentos da Verdade", para simbolizar o momento em que o cliente entra em contato com algum aspecto da empresa fornecedora do serviço. A avaliação da qualidade do serviço pelo cliente será o resultado da somatória da qualidade percebida em todos os momentos da verdade, vivenciados ao longo do processo de prestação do serviço.

A sucessão de momentos da verdade foi chamada por Shostack (1985) de "Fluxo de Processo de Serviço" (FPS), que foi proposto como uma ferramenta de engenharia no desenvolvimento de sistemas de prestação de serviço. A elaboração do FPS inicia-se com o mapeamento dos momentos da verdade vivenciados pelo cliente. Em seguida, identificam-se as interações entre o cliente e o pessoal de contato, definindo-se as atividades destes últimos. Sucessivamente, avança-se na descrição das atividades do pessoal de suporte, produção e gerência.

Tendo-se analisado quais os momentos da verdade são críticos para a percepção da qualidade dos clientes, pode-se identificar quais atividades dentro da organização - ou, ainda, quais fluxos de atividades - têm papel essencial na percepção do desempenho da empresa pelo cliente.

A proposta inicial de Schostack (1985) foi a utilização do FPS como ferramenta de análise comparativa de processos substitutivos, na qual alternativas de aumentar ou diminuir a complexidade e a divergência do processo, como um todo, permitem avaliar escolhas estratégicas. Todavia, num processo de melhoria de um serviço existente, a atividade de melhoria em si não é claramente definida quanto a quais técnicas ou ferramentas aplicar para se chegar a uma ação efetiva (GIANESI, 1994).

Normalmente, os grupos de trabalho confiam no conhecimento técnico dos participantes para as ações corretivas necessárias. Um problema comum que ocorre durante os trabalhos destes grupos é que seus participantes não percebem a existência de um ponto cego nos muitos sistemas de fornecimento de serviço, que é a capacidade de o provedor perceber que alguma coisa pode dar errada.

Quando o trabalho é feito no desenvolvimento de produtos, leva-se em conta a possibilidade de perdas, estragos, erros e unidades defeituosas que não atendam às especificações. Nestes casos está se tornando comum o uso da técnica Análise do Efeito e Modo da Falha (FMEA) como ferramenta de prevenção. Esta técnica é bem definida nos manuais da QS9000 (FMEA, 2001), bem como na bibliografia sobre o assunto, tais como Juran (1988) e Stamatis (1995).

Dentro das Operações de Serviço, esta metodologia tem sido indicada principalmente pela bibliografia que se refere à técnica de FMEA, como Stamatis (1995). A bibliografia da área de Serviços, como Johnston (2001), Fitzsimmons (2000) e Albrecht (2002), traz referências sobre ações preventivas, através do uso de dispositivos poka yoke (JOHNSTON; CLARK, 2001), mas pouca ou nenhuma referência ao uso do FMEA como técnica preventiva.

A aplicação deste método não diferencia as ações da linha de frente (front office), em que o cliente está presente, das ações da retaguarda (back room), de suporte e prepara- 
tórias do serviço (GIANESI, 1994). Todavia, quando o cliente está presente e a produção e entrega do serviço ocorrem simultaneamente, existem componentes de incerteza que devem ser tratados de forma diferente e, portanto, a adaptação da ferramenta FMEA pode ser essencial para uma boa ação preventiva.

\section{MODELO PROPOSTO}

Nossa proposta consiste em adaptar o FMEA clássico, incorporando elementos que atendam aos aspectos da prestação de Serviços nos casos apontados no item anterior. Vamos chamar esta técnica de SFMEA - Análise do Efeito e Modo da Falha em Serviços.

Em linhas gerais, esta técnica inicialmente desenha o fluxo de prestação do serviço FPS como base para determinar os momentos da verdade e caracterizá-los quanto à sua importância para o sucesso do Serviço. Para cada momento da verdade crítico, são feitas as seguintes verificações: que tipo de falhas podem ocorrer durante sua execução, o modo como estas falhas podem ocorrer, os efeitos sobre o cliente caso a falha ocorra, os controles existentes nas fases anteriores à execução do serviço e, caso ocorra a falha, o que deve ser feito para recuperar a satisfação do cliente.

Dois aspectos diferenciam esta técnica do FMEA tradicional: primeiro, os controles existentes são aqueles presentes nas fases de preparação do serviço, ou na retaguarda (back room) (GIANESI, 1994), sendo aqueles processos que ocorrem antes da execução do serviço na frente do cliente. O segundo aspecto trata da correção de erros cometidos no momento da prestação do serviço, ou seja, na frente do cliente. $\mathrm{O}$ modelo ora proposto diferencia-se do FMEA original, pois acrescenta as características típicas da linha de frente (front office) de serviços.

É possível, na prestação do serviço, que assim que ocorra a falha na presença do cliente o processo atue no sentido de recuperá-la e reduzir seu efeito perante ao cliente (ALBRECHT, 2002). Há casos em que a pronta recuperação torna o cliente satisfeito e mais seguro em relação ao serviço prestado (BITNER et al., 1990). Por exemplo: um cliente aluga um carro em uma empresa de locação de automóveis e quando vai receber o carro, após preencher todas as formalidades, verifica que o mesmo está com a bateria descarregada; o gerente da empresa oferece no lugar um outro carro de uma categoria melhor; o cliente fica satisfeito e passa a confiar na empresa que o tratou tão bem. Este tipo de atividade foi denominada por Albrecht (2002) de Recuperação.

Este é um importante ponto de diferenciação entre produto e serviço e sua análise permite ações preventivas na execução do serviço. Se alguma coisa der errado, alguém sairá de sua rotina para fazer os acertos esperados pelo cliente? Alguém se empenha em compensar o impacto negativo sobre o cliente? Alguém sabe, ao menos, quando ou como simplesmente desculpar-se?

Albrecht (2002) coloca que um sistema eficaz de recuperação de serviços deve considerar duas possíveis formas como o cliente sente o problema: ele pode ficar aborrecido, isto é, com uma irritação branda, caso o serviço fique um pouco aquém das suas perspectivas, ou com um sentimento de vítima, que ocorre quando o cliente fica numa situação precária, criando uma situação de ruptura mais séria, com surtos de raiva, frustração e dor.

Para Zemke (2000), o prestador do Serviço deve levar em conta os seguintes cinco elementos para uma Recuperação eficaz:

1- Desculpas: É necessário um reconhecimento, por parte do provedor do serviço, do erro imediatamente após a falha do serviço. A desculpa deve demonstrar que o provedor assume a responsabilidade e que reconhece, em nome da organização, que o cliente foi maltratado.

2- Reparação urgente: Às vezes só o pedido de desculpas não basta, o cliente deve perceber que o provedor do serviço está fazendo o possível para restabelecer o equilíbrio sem demora. No caso em que ele, cliente, se sente como vítima, a recuperação é mais complexa, exigindo a complementação com os próximo três itens.

3- Empatia: "Sei como você está se sentindo, me importo com você e sou solidário com o problema". É importante que o cliente sinta que o provedor compartilha o problema e não que ele, provedor, tem pena dele, cliente.

4- "Isto é por nossa conta": O cliente está numa fila de restaurante para almoçar nos trinta minutos que sua atividade permite; após uma espera além do normal o pedido fica pronto e o cliente fica cara a cara com o atendente. Antes que o cliente reclame, o atendente diz: "Puxa vida, hoje demorou mais do que o normal, mas para compensálo vamos dar uma porção de batatas fritas grande no lugar da pequena, espero vê-lo de novo". O atendente foi preparado para ter este comportamento.

5- "Pisamos na bola, mas tudo está bem agora": A recuperação deve prever alguma forma de confirmação que foi eficaz. Muitas vezes isto ocorre no momento da recuperação com um sorriso ou brincadeira do cliente, outras vezes requer um contato extra com o cliente para confirmar o que foi feito. Neste momento, o atendente que sofreu o problema junto ao cliente tem sua auto-estima promovida e, portanto, se sente com energia e confiança para continuar seu trabalho.

Quando os grupos preparam ações para recuperar os serviços se ocorrerem falhas, estão convertendo estas falhas em atos positivos para o cliente e para o negócio. 


\section{SFMEA: ANÁLISE DO EFEITO E MODO DE FALHA EM SERVIC̣OS - APLICANDO A METODOLOGIA}

Basicamente esta ferramenta se baseia na metodologia FMEA, que foi desenvolvida para identificar como um produto pode fracassar em proporcionar a função intencionada para o cliente (JURAN, 1988).

O SFMEA é um método estruturado para:

- Identificar como um processo pode fracassar em atender os requisitos críticos dos clientes.

- Estimar o risco de causas específicas em relação a estas falhas.

- Avaliar o plano de controle atual no que diz respeito à PREVENÇÃO destas falhas.

- Recuperar o cliente com ações imediatas caso ocorram problemas na entrega do serviço.

- Implantar as ações que devem ser tomadas para tornar o processo à prova de erros.

De modo a facilitar o trabalho, tradicionalmente utilizase uma planilha, conforme mostra a Figura 1, cujos itens são definidos abaixo:

a. Momento da Verdade: Pontos do FPS onde o cliente entra em contato com algum aspecto do serviço.

b. Modo de Falha Potencial: É a maneira pela qual um processo poderá vir a falhar em atender aos requisitos de processo e/ou objetivo do serviço. É a descrição da não conformidade em uma dada operação.

Lista cada tipo de falha potencial, para cada operação em particular, em termos de componentes, subsistema ou característica do processo do serviço.

Responder às seguintes questões poderá ajudar a encontrar tipos de falhas potenciais:

- Como poderá o processo/serviço falhar em atender às especificações?

- Independentemente das especificações do Serviço, o que um cliente (usuário final) consideraria questionável?

c. Efeito Potencial da Falha: São os efeitos do tipo de falha sobre o(s) cliente(s), descritos em termos do que o cliente poderá observar.

Os efeitos deverão ser escritos em termos de desempenho do serviço, tais como: emoções negativas do cliente como raiva contra os atendentes, medo dos possíveis resultados do serviço em relação à sua pessoa, insatisfação quanto a ter suas expectativas atendidas, tédio, ou o produto que recebe junto ao serviço estar com problemas.

d. (S) - Severidade (do efeito): Importância do efeito sobre os requisitos do cliente, também poderia estar ligado a segurança ou outros riscos caso a falha ocorra.

Escala de Likert: de 1 a 5

1- Não severo. Ex.: Cliente não percebe, ou fica ligeiramente aborrecido.

5- Muito severo. Ex.: Cliente em apuros ou muito aborrecido devido ao efeito adverso no desempenho do serviço. Sentimento de vítima.

e. Causas/Mecanismos de Falha: É a maneira como a falha pode ocorrer, descrita em termos de algo que possa ser corrigido ou controlado. Para todo tipo de falha potencial, devem-se listar as possíveis causas.

Se uma causa é exclusiva para um modo de falha, ou seja, se a correção da causa tiver um impacto direto no tipo de falha, então esta parte do SFMEA estará finalizada. Muitas causas, entretanto, para serem prevenidas de modo efetivo, exigem que sejam utilizadas técnicas de análise de falhas para determinar quais causas-raízes são as mais significativas e qual pode ser mais facilmente controlada. Exemplo de causas típicas de falhas:

Ausência de procedimentos definidos, treinamento inadequado ou inexistente dos funcionários, má compreensão das necessidades do cliente, atividades do backroom deficientes, etc.

f. (O) - Ocorrência (da causa): Frequiência com que uma dada causa ocorre e gera um modo de falha.

Escala de Likert: de 1 a 5

1- Probabilidade remota de ocorrência.

5- Falha certa baseada nos dados obtidos.

Figura 1: Matriz do SFMEA

ANÁLISE DE MODO E EFEITOS DE FALHA POTENCIAL EM SERVIC̣OS (SFMEA]

Descrição do Serviço:

Item:

SFMEA $\mathrm{n}$ ㅇ:

Responsável pelo Projeto:

Equipe:

Data SFMEA:

\begin{tabular}{|c|c|c|c|c|c|c|c|c|c|c|c|c|c|c|c|c|c|c|}
\hline $\begin{array}{c}\text { Momento } \\
\text { da } \\
\text { Verdade }\end{array}$ & $\begin{array}{l}\text { Modo de } \\
\text { Falha } \\
\text { Potencial }\end{array}$ & $\begin{array}{c}\text { Efeitos } \\
\text { Potenciais }\end{array}$ & S & $\begin{array}{c}\text { Causas } \\
\text { Potenciais }\end{array}$ & 0 & Controles & D & Recuperação & $\mathbf{R}$ & $\begin{array}{l}\mathrm{R} \\
\mathrm{P} \\
\mathrm{N}\end{array}$ & $\begin{array}{c}\text { AÇÕES } \\
\text { PREVENTIVAS }\end{array}$ & RESPONSÁVEIS & $\begin{array}{c}\text { AC̣ÕES } \\
\text { TOMADAS }\end{array}$ & S & 0 & D & $\mathbf{R}$ & $\begin{array}{l}R \\
P \\
N\end{array}$ \\
\hline & & & & & & & & & & & & & & & & & & \\
\hline & & & & & & & & & & & & & & & & & & \\
\hline
\end{tabular}


g. Controles de Processos Atuais: São controles que impedem a ocorrência do tipo de falha ou detectam o tipo de falha que viria a ocorrer. No caso de serviços, trata-se dos controles existentes no backroom e aqueles possíveis de serem feitos antes que o cliente esteja presente na operação do serviço.

Estes controles podem ser controles de processo que impedem a ocorrência da causa/mecanismo ou tipo/efeito da falha, ou que reduzem a possibilidade destas ocorrerem.

h. (D) - Detecção: Capacidade de o sistema detectar as causas antes de a falha ocorrer, ou de detectar a falha antes do cliente. Assume-se que a falha ocorreu e então avalia-se a capacidade de todos os "Controles de Processos Atuais" prevenirem a ocorrência de falha ou defeito durante a prestação do serviço. Não se assume automaticamente que a nota de detecção é baixa porque a nota de ocorrência é baixa, mas avalie a capacidade dos controles de processo detectarem um tipo de falha de baixa freqüência ou preveni-los de seguir adiante no processo.

Verificações esporádica de qualidade são improváveis de detectar a existência de uma falha isolada e não devem influenciar na nota de detecção. Amostras tomadas com base estatística são controles de detecção válidos.

Escala de Likert: de 1 a 5

1- Certeza de encontrar ou prevenir a falha antes de atingir o cliente.

5- Os controles atuais não vão, com certeza, detectar a falha.

i. (R) - Recuperação: É possível, na prestação do serviço, que assim que ocorra a falha na presença do cliente o processo atue no sentido de recuperá-la e reduzir seu efeito perante o cliente (ALBRECHT, 2002).

$\mathrm{O}$ índice de Recuperação (R) mede a capacidade de o processo recuperar o serviço antes de o cliente perceber a falha, ou de recuperar assim que o cliente percebe, de forma que ele aceite a recuperação.

Escala de Likert: de 1 a 5

1- Existe um processo de recuperação definido e ele ocorre antes de o cliente perceber a falha.

5- Não há recuperação do serviço.

j. Número de Prioridade de Risco (RPN): Esse valor deve ser usado para estabelecer as prioridades no processo. Para altos RPNs, a equipe deve empreender esforços para reduzir o risco calculado, promovendo ações preventivas. Como prática geral, quando houver uma nota alta de severidade, deve ser dada atenção especial a esta falha, independente do valor do RPN.

Normalmente não há uma regra rigorosamente definida para se estabelecer qual o RPN limite, aquele que define qual o número máximo de risco que se deve suportar. $\mathrm{O}$ grupo de estudos deve levar em conta fatores de risco, custo e competitividade da empresa.

Quando, por exemplo, fatores de risco de vida ou de injúria séria a alguém estão envolvidos, o RPN utilizado como mínimo para gerar ações preventivas é sempre muito baixo. O RPN é calculado baseando-se nas informações relativas ao modo de falha potencial, à severidade da falha e à capacidade do sistema de detectar as falhas antes de chegarem ao cliente. Para isto, fazemos a avaliação de cada ponto em termos dos índices de: (S) Severidade, $(\mathrm{O})$ Ocorrência, (D) Deteç̧ão e (R) Recuperação e calculamos: $R P N=(S) \times(0) \times(D) \times(R)$.

k. Responsáveis: Deve ser claramente definido quem será o responsável pela implantação das ações preventivas.

1. Ações Recomendadas: São as ações que devem ser aplicadas tanto no front office como no backroom, que modifiquem o processo de prestação de serviço de modo a torná-lo à prova de erros.

m. Ações Tomadas: Após a implementação da ação, preencher com uma breve descrição da ação tomada e a data de realização.

n. RPN Resultante: Depois de definida a ação corretiva, devem-se estimar os novos índices e calcular o RPN.

Caso os RPNs resultantes não atinjam os valores abaixo do valor máximo estabelecido, o processo deve ser revisado e outras ações tomadas.

\section{ESTUDOS DE CASOS}

Para exemplificar a utilização da metodologia, vamos mostrar a sua aplicação na melhoria dos serviços prestados em duas situações diferentes. Primeiro, para um restaurante de uma Clínica Médica de emagrecimento, segundo para um setor de atendimento de ambulatório médico.

\section{Restaurante de uma Clínica Médica de emagrecimento}

Foi escolhido para o estudo o restaurante da clínica, pois neste tipo de atividade as refeições em si, o local e a forma como são oferecidas são muito críticos para o sucesso do tratamento e a satisfação do cliente.

Foi organizado um grupo de SFMEA, composto por 8 elementos pertencentes à área. É fortemente recomendado que os participantes tenham vivência na área, pois a ferramenta é baseada na experiência do grupo. Foi oferecido um treinamento em técnicas de fluxograma e de SFMEA para os elementos do grupo. 
No início dos trabalhos foram detectados problemas de liderança entre os participantes, e assim sendo, foi decidido também treinar um elemento em dinâmica de grupo para ser o facilitador dos trabalhos. a. Determinando o Fluxo do Processo de Serviço

A primeira parte dos trabalhos do grupo foi elaborar o FPS no restaurante, baseados nos momentos da verdade por que passa o cliente.

Figura 2: Fluxo do Processo de Serviço do Restaurante da Clínica Médica

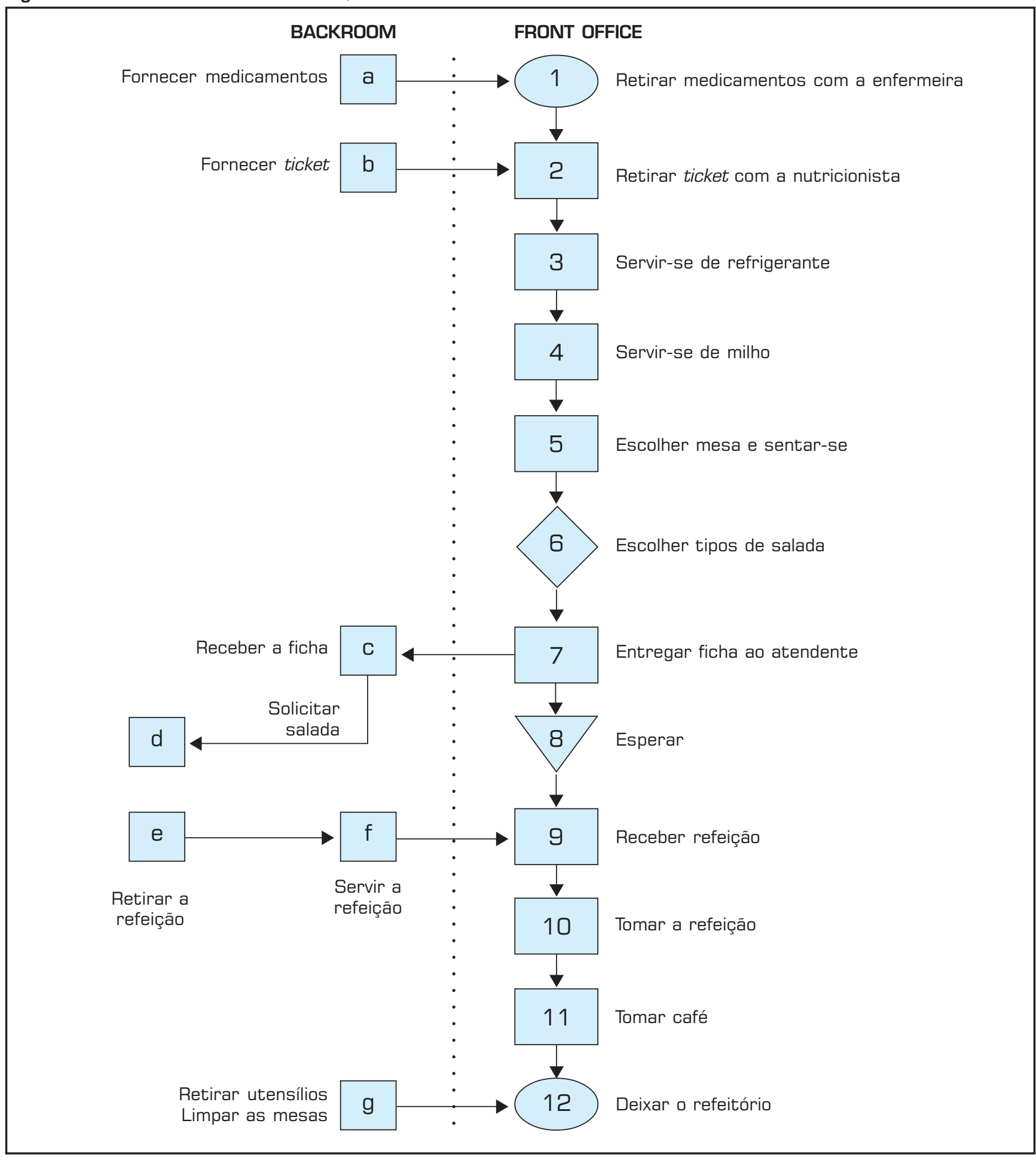


Foram identificadas duas linhas: $\mathrm{O}$ front office, onde o cliente vivencia experiências, seja em contato com os utensílios, móveis ou a própria refeição, seja em contato com os próprios funcionários do restaurante. A outra linha é o back room, onde são realizadas as atividades de apoio para o front office. A linha do front office, portanto, representa a seqüência de momentos da verdade e, por conseqüência, o Fluxo de Serviço. Cada momento da verdade corresponde a um ponto a ser analisado utilizando-se a ferramenta SFMEA. O fluxo foi desenhado conforme é mostrado na Figura 2.

\section{b. Aplicação do SFMEA}

Após análise, o grupo chegou a um padrão para os serviços entregues nos momentos da verdade estudados, decidindo utilizar como referência para os trabalhos os RPNs mais críticos entre os grupos e ter como valor limite para estudo o RPN mínimo de 50 pontos.

Na Figura 3 é apresentada a matriz de SFMEA para alguns momentos da verdade do processo do restaurante da clínica médica.

\section{c. Ações Preventivas}

O grupo fez uma análise das possíveis falhas e propôs ações preventivas no processo atual para eliminar ou minimizar a possibilidade de ocorrência e recuperar a falha, caso esta venha a acorrer.

Um novo índice RPN foi calculado, supondo-se que a ação seja implantada com sucesso.

Para efeito deste trabalho, vamos comentar dois dos itens estudados.

- Falha 1 - MESAS MAL ARRUMADAS

Ações preventivas: Estabelecer um padrão para definir o que é uma mesa arrumada. Treinar os operadores com o novo padrão. Estabelecer um inspeção contínua por parte da chefia, que deve dar uma nota no final do seu período para o item "Mesa arrumada".

Indicadores: $\mathrm{S}=3, \mathrm{O}=3, \mathrm{D}=1, \mathrm{R}=2$

$\mathrm{RPN}=18$

- Falha 2 - FUNCIONÁRIO DESCORTÊS

Ações preventivas: Treinamento dos funcionários no contato com os pacientes.

Entrevistas mensais dos funcionários com a chefia para avaliação dos contatos com os clientes e para discutir problemas pessoais do funcionário.

Estabelecer um sistema de reconhecimento das boas ações praticadas pelos funcionários.

Quando ocorrer o problema, o chefe deve polidamente pedir desculpas ao cliente, informando-o de que será tomada uma ação corretiva apropriada. Na saída será entregue um vaso de flores ao cliente.

Indicadores: $\mathrm{S}=4, \mathrm{O}=2, \mathrm{D}=2, \mathrm{R}=2$

$\mathrm{RPN}=32$

Comentários: Considerando a condição do cliente que está sendo submetido a um regime alimentar e, portanto, com a sua sensibilidade alterada, é provável que ele facilmente se sinta como "Vítima" nestes casos. Por outro lado, devemos levar em conta no treinamento para as ações de recuperação a auto-estima do funcionário. Quando possível, devemos consultar o pessoal de RH como suporte para as ações de prevenção e de recuperação necessárias.

\section{Ambulatório Médico de uma empresa}

$\mathrm{O}$ ambulatório visitado oferece atendimento médico e

Figura 3 - Matriz de SFMEA do Restaurante da Clínica Médica

\begin{tabular}{|c|c|c|c|c|c|c|c|c|c|c|c|c|c|c|c|c|c|c|}
\hline \multicolumn{19}{|c|}{ ANÁLISE DE MODO E EFEITOS DE FALHA POTENCIAL EM SERVIC̣OS (SFMEA) } \\
\hline \multicolumn{6}{|c|}{$\begin{array}{l}\text { Descrição do Serviço: } \\
\text { Responsável pelo Projeto: }\end{array}$} & \multicolumn{5}{|c|}{$\begin{array}{l}\text { Item: } \\
\text { Equipe: }\end{array}$} & \multicolumn{8}{|c|}{$\begin{array}{l}\text { SFMEA n: } \\
\text { Data SFMEA: }\end{array}$} \\
\hline $\begin{array}{l}\text { Momento } \\
\text { da } \\
\text { Verdade }\end{array}$ & $\begin{array}{c}\text { Modo de } \\
\text { Falha } \\
\text { Potencial }\end{array}$ & $\begin{array}{c}\text { Efeitos } \\
\text { Potenciais }\end{array}$ & S & \begin{tabular}{c|} 
Causas \\
Potenciais
\end{tabular} & 0 & Controles & D & Recuperação & $\mathbf{R}$ & $\begin{array}{l}\mathrm{R} \\
\mathrm{P} \\
\mathrm{N}\end{array}$ & $\begin{array}{c}\text { AC̣ÕES } \\
\text { PREVENTIVAS }\end{array}$ & RESPONSÁVEIS & $\begin{array}{c}\text { AC̣̃̃ES } \\
\text { TOMADAS }\end{array}$ & S & 0 & D & $R$ & $\begin{array}{l}\mathrm{R} \\
\mathrm{P} \\
\mathrm{N}\end{array}$ \\
\hline $\begin{array}{l}\text { Escolher } \\
\text { mesa e } \\
\text { sentar- } \\
\text { se }\end{array}$ & \begin{tabular}{l|} 
Mesas \\
mal \\
arrumadas
\end{tabular} & $\begin{array}{l}0 \text { cliente } \\
\text { insatisfeito } \\
\text { reclama e } \\
\text { afeta o } \\
\text { fluxo }\end{array}$ & 3 & $\begin{array}{l}\text { Falta de } \\
\text { padrões } \\
\text { Funcioná- } \\
\text { rios mal } \\
\text { treinados }\end{array}$ & 5 & $\begin{array}{l}\text { O próprio } \\
\text { funcionário } \\
\text { inspeciona }\end{array}$ & 3 & \begin{tabular}{|l} 
O \\
funcionário \\
arruma a \\
mesa e se \\
desculpa
\end{tabular} & 2 & 90 & $\begin{array}{l}\text { Treinamento } \\
\text { dos funcionários, } \\
\text { elaborar padrão } \\
\text { para as mesas } \\
\text { Desenvolver } \\
\text { uma inspeção } \\
\text { contínua pelos } \\
\text { encarregados }\end{array}$ & $\begin{array}{l}\text { Chefia e grupo } \\
\text { de SFMEA } \\
\end{array}$ & $\begin{array}{l}\text { As ações } \\
\text { serão } \\
\text { tomadas e } \\
\text { implemen- } \\
\text { tadas em } \\
30 \text { dias }\end{array}$ & 3 & 3 & 1 & 2 & 18 \\
\hline $\begin{array}{l}\text { Retirar } \\
\text { tickets } \\
\text { Retirar } \\
\text { medica- } \\
\text { mentos } \\
\text { Receber } \\
\text { a refeição }\end{array}$ & $\begin{array}{l}\text { Funcioná- } \\
\text { rio } \\
\text { descortês }\end{array}$ & \begin{tabular}{|l} 
Cliente \\
insatisfeito \\
provoca \\
bate-boca
\end{tabular} & 4 & $\begin{array}{l}\text { Funcioná- } \\
\text { rios mal } \\
\text { treinados }\end{array}$ & 5 & $\begin{array}{l}\text { Somente } \\
\text { quando o } \\
\text { cliente } \\
\text { reclama }\end{array}$ & 3 & $\begin{array}{l}\text { Não há um } \\
\text { processo } \\
\text { definido }\end{array}$ & 5 & 225 & $\begin{array}{l}\text { Treinamento } \\
\text { dos funcionários, } \\
\text { Reuniões } \\
\text { periódicas } \\
\text { com a chefia }\end{array}$ & Chefia & $\begin{array}{l}\text { As ações } \\
\text { serão } \\
\text { tomadas e } \\
\text { implementa- } \\
\text { das em } 30 \\
\text { dias }\end{array}$ & 4 & 2 & 2 & 2 & 32 \\
\hline
\end{tabular}


odontológico a uma população que corresponde a cerca de 1.000 pessoas, com seus dependentes.

\section{a. Análise do Processo de Prestação dos Serviços}

Na Figura 4 observou-se que o fluxo basicamente se inicia no guichê de atendimento, com a identificação do paciente pela atendente e a indagação sobre sua necessidade. Neste momento, a atendente orienta o paciente a retirar uma senha numerada pré-impressa de um dispositivo instalado naquele local, que permite à atendente registrar o número e o tipo de atendimento a ser prestado ao cliente, que o associa ao número da sala para onde este será encaminhado (neste momento a atendente repassa a informação para o back room a fim de retirar o prontuário do funcionário e disponibilizá-lo ao profissional que irá atendê-lo).

Após esta etapa, segue-se um período de espera, em que o paciente aguarda sentado. Alguns itens de conforto foram observados, tais como: bebedouros e aparelhos de TV, além da proximidade a elevadores e sanitários.

Além disso, existe uma sinalização interna e um display eletrônico orientador das chamadas informando o número da senha e da sala para onde deve se dirigir o paciente.

A próxima fase consiste na entrada do paciente na área interna do ambulatório, somente permitida àqueles previamente chamados/anunciados pelo display, através do acionamento de um dispositivo eletroportátil pelo médico, de dentro do seu consultório.

$\mathrm{O}$ atendimento ocorre nos consultórios médicos situados na área interna ou, excepcionalmente, na enfermaria, e é a etapa mais importante de todo o fluxo, pois é onde a interação paciente/prestador do serviço é mais intensa e se prolonga por maior tempo.

Após o paciente sair do consultório, este retorna ao guichê, caso necessite de emissão de guia para exame complementar e/ou agendamento de retorno, e cumpre mais um período de espera na área de recepção, se for o caso da emissão de guias médicas, e sai definitivamente do ambulatório, finalizando assim seu trâmite no fluxo do processo de serviço.

\section{b. Aplicação do SFMEA}

Na Figura 5 é apresentada a matriz de SFMEA para alguns momentos da verdade do processo do serviço do ambulatório médico.

Após análise, o grupo chegou a um valor limite para o RPN de no mínimo 40 pontos.

\section{c. Ações Preventivas}

O grupo fez uma análise das possíveis falhas e propôs ações preventivas no processo atual para eliminar ou minimizar a possibilidade de ocorrência e para recuperar a falha, caso esta venha a ocorrer.

Para efeito deste trabalho, vamos comentar dois dos itens estudados.

- FAlHA 1 - TEMPO DE ESPERA MUITO LONGO PARA SER ATENDIDO

Ações preventivas: Reforço da supervisão e estudo da capacidade da demanda (estudo de filas e pré-agendamento).

Colocar fitas de vídeo com filmes e programas alegres. Novo RPN $=20$.

\section{- FALHA 2 - RETORNO AO GUICHÊ PARA MARCAR} RETORNO, EXTRAVIO DA AGENDA

Ações preventivas: Admissão criteriosa e uso de testes para os funcionários.

Revisão dos procedimentos operacionais e treinamento dos funcionários na rotina.

Treinar funcionário para se desculpar em nome da organização. Contato com supervisor para acelerar o processo. Novo RPN $=8$.

\section{CONCLUSÕES}

Apesar da dificuldade em determinar conceitos e valores para as falhas potenciais detectadas na prestação de serviços, a aplicação desta técnica demonstra ser efetiva na priorização dos pontos críticos urgentes para receberem ações preventivas. Os participantes do grupo adquirem uma

Figura 4: Fluxo do Processo de Serviço do Ambulatório Médico

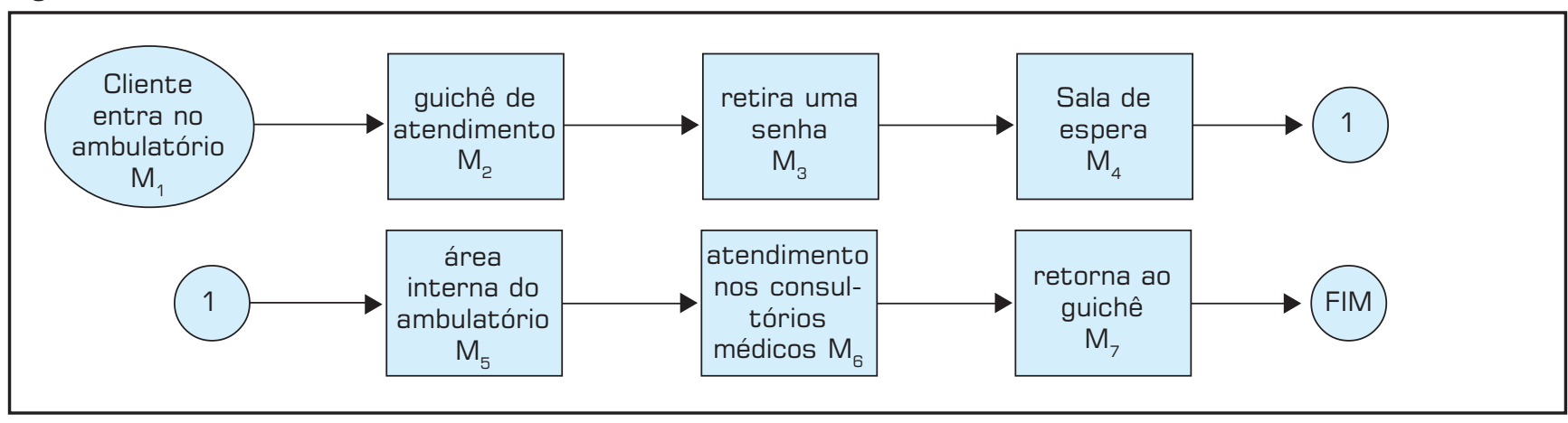


visão melhorada de todo o processo, tanto da linha de frente (front office) como da retaguarda (backroom), reforçando as atividades que podem provocar problemas na frente do cliente.

A visão da possibilidade de ações de Recuperação por parte da equipe não só é importante no preparo para um possível problema, mas também para uma discussão sobre a autoridade que um elemento da linha de frente deve ter para tomar decisões que envolvam valores para a companhia. Nos dois casos apresentados observa-se que a análise da possibilidade de ocorrência do problema e da conseqüente ação de recuperação foi considerada de uma forma que o grupo considerou adequada.

Um outro fator conclusivo é que, a partir da aplicação das ações preventivas, esta ferramenta pode ser novamente utilizada e, assim, dar continuidade a um ciclo de melhorias na empresa, característico de sistemas de gestão voltados à obtenção da qualidade.

Partindo dos momentos da verdade e melhorando tanto o front office como o backroom, o SFMEA é um método poderoso para garantir a satisfação do cliente.

Figura 5: Matriz de SFMEA do Ambulatório Médico

\begin{tabular}{|c|c|c|c|c|c|c|c|c|c|c|c|c|c|c|c|c|c|c|}
\hline \multicolumn{19}{|c|}{ ANÁLISE DE MODO E EFEITOS DE FALHA POTENCIAL EM SERVIC̣OS (SFMEA] } \\
\hline $\begin{array}{l}\text { Descriç } \\
\text { Respon }\end{array}$ & $\begin{array}{l}\text { ão do Se } \\
\text { sável pel }\end{array}$ & $\begin{array}{l}\text { arviço: } \\
\text { o Projeto }\end{array}$ & & & & $\begin{array}{l}\text { It } \\
\text { Ec }\end{array}$ & $\begin{array}{l}\text { qui } \\
\text { qum }\end{array}$ & & & & & $\begin{array}{l}\text { SFME } \\
\text { Data }\end{array}$ & $\begin{array}{l}\text { A no: } \\
\text { SFMEA: }\end{array}$ & & & & & \\
\hline $\begin{array}{c}\text { Momento } \\
\text { da } \\
\text { Verdade }\end{array}$ & \begin{tabular}{|l} 
Modo de \\
Falha \\
Potencial
\end{tabular} & $\begin{array}{c}\text { Efeitos } \\
\text { Potenciais }\end{array}$ & $\begin{array}{l}\mathrm{S} \\
\mathrm{E} \\
\mathrm{V}\end{array}$ & \begin{tabular}{|c|} 
Causas \\
Potenciais
\end{tabular} & $\begin{array}{l}0 \\
C \\
0\end{array}$ & Controles & \begin{tabular}{|l|}
$D$ \\
$E$ \\
$T$ \\
\end{tabular} & Recuperação & $\begin{array}{l}\mathrm{R} \\
\mathrm{E} \\
\mathrm{C}\end{array}$ & $\begin{array}{l}\mathrm{R} \\
\mathrm{P} \\
\mathrm{N}\end{array}$ & $\begin{array}{c}\text { AČ̃̃ES } \\
\text { PREVENTIVAS }\end{array}$ & \begin{tabular}{|l} 
RESPON- \\
SÁVEIS
\end{tabular} & $\begin{array}{l}\text { AC̣ÕES } \\
\text { TOMADAS }\end{array}$ & $\begin{array}{l}\text { S } \\
E \\
V\end{array}$ & $\begin{array}{l}0 \\
\mathrm{C} \\
0\end{array}$ & $\begin{array}{l}\mathrm{D} \\
\mathrm{E} \\
\mathrm{T}\end{array}$ & $\begin{array}{l}\text { R } \\
\mathrm{E} \\
\mathrm{C}\end{array}$ & $\begin{array}{l}\mathrm{R} \\
\mathrm{P} \\
\mathrm{N}\end{array}$ \\
\hline \begin{tabular}{|l} 
Sala de \\
espera \\
M4
\end{tabular} & \begin{tabular}{|l|} 
Tempo de \\
espera \\
muito \\
longo
\end{tabular} & $\begin{array}{l}\text { Paciente } \\
\text { insatisfeito }\end{array}$ & 5 & \begin{tabular}{|l|} 
Demanda \\
maior do \\
que a \\
capacidade \\
Falta de \\
profissional
\end{tabular} & 4 & \begin{tabular}{|l|} 
Avaliação \\
contínua. \\
Quantidade \\
de recla- \\
mações/ \\
sugestões \\
apresen- \\
tadas \\
\end{tabular} & 2 & \begin{tabular}{|l} 
Ligar \\
televisor na \\
área de \\
espera. \\
Fornecer \\
café e \\
bolachas
\end{tabular} & 3 & 120 & $\begin{array}{l}\text { Reforço da super- } \\
\text { visão e estudo da } \\
\text { capacidade da } \\
\text { demanda (estudo } \\
\text { de filas e pré- } \\
\text { agendamento) }\end{array}$ & $\begin{array}{l}\text { Gerente } \\
\text { do } \\
\text { Ambu- } \\
\text { latório }\end{array}$ & \begin{tabular}{|l} 
Reforço da \\
supervisão e \\
adequação da \\
capacidade de \\
atendimento
\end{tabular} & 2 & 2 & 5 & 1 & 20 \\
\hline $\begin{array}{l}\text { Retorno } \\
\text { ao guichê } \\
\text { para } \\
\text { marcar } \\
\text { retorno } \\
\text { M7 }\end{array}$ & $\begin{array}{l}\text { Extravio } \\
\text { da } \\
\text { agenda }\end{array}$ & $\begin{array}{l}\text { Paciente } \\
\text { insatisfeito }\end{array}$ & 5 & \begin{tabular}{|l|} 
Má \\
formação \\
do \\
profissional \\
Sistema \\
inoperante
\end{tabular} & 1 & $\begin{array}{l}\text { Sistema } \\
\text { de recla- } \\
\text { mações } \\
\text { Manuten- } \\
\text { ção do } \\
\text { sistema }\end{array}$ & 4 & Não existe & 5 & 100 & $\begin{array}{l}\text { Admissão criterio- } \\
\text { sa e uso de testes } \\
\text { para os funcionários } \\
\text { Revisão dos } \\
\text { procedimentos } \\
\text { operacionais e } \\
\text { treinamento dos } \\
\text { funcionários na } \\
\text { rotina } \\
\text { Treinar funcionário } \\
\text { para se desculpar } \\
\text { em nome da } \\
\text { organização. } \\
\text { Contato com } \\
\text { supervisor para } \\
\text { acelerar o } \\
\text { processo }\end{array}$ & $\begin{array}{l}\text { Gerente } \\
\text { da Área }\end{array}$ & $\begin{array}{l}\text { Avaliação } \\
\text { antecipada e } \\
\text { continuada do } \\
\text { profissional } \\
\text { Treinar } \\
\text { funcionários } \\
\text { para uma } \\
\text { comunicação } \\
\text { eficiente com } \\
\text { o cliente } \\
\text { Desenvolver } \\
\text { ações para } \\
\text { compensar o } \\
\text { sistema }\end{array}$ & 1 & 1 & 4 & 2 & 8 \\
\hline
\end{tabular}

\section{- Bibliografia}

BITNER, M. J.; BOOMS, B.H.; TETREAULT, M. S. The Service Encounter: Diagnosing favorable and unfavorable incidents, Journal of Marketing, v. 54, p.71-87, 1990.

FMEA, Análise de Modo e Efeitos de Falha Potencial. Manual de Referência Instituto da Qualidade Automotiva 1997

PPAP Processos de Aprovação de Peças de Produção. Manual de Referência. Instituto da Qualidade Automotiva 2000

CARLZON, JAN. A Hora da Verdade. Rio de Janeiro: COP Editora, 1985.
GIANESI, I.N. \& CORREA, H.L. Administração Estratégica de Serviços Operações para Satisfação do Cliente. São Paulo: Editora Atlas, 1994.

JOHNSTON, R; CLARK, G. Service Operations Management. New Jersey: Prentice Hall, 2001.

JURAN, J.M. Juran's Quality Control Handbook, 4ed. New York: MacGrawHill, 1988.

GRÖNROOS, C. Marketing, Gerenciamento e Serviços - A Competição por Serviços na Hora da Verdade, Rio de Janeiro: Editora Campos, 1995.
HALBRECHT, K.; ZEMKE, R. Serviço ao Cliente. Rio de Janeiro: Editora Campus, 2002.

HARKER, Patrick T. (Editor). The Service Productivity and Quality Challenge. International Studies in the Service Economy, v.5, Dordrecht (Netherlands): Kulwer Academic Publishers, 1995.

KARL A.R.Z. Serviço ao Cliente: A Reivindicação da Gestão do atendimento ao cliente. Rio de Janeiro: Ed. Campus, 2002

NORMANN, R. Administração de Serviços: Estratégia e liderança na empresa de serviços. São Paulo: Atlas, 1993.
PARASURAMAN, A.; ZEITHMAL, V. A.; BERRY, L. L. Delivering service quality: balancing customer perceptions and expectations. New York: The Free Press, 1990.

SHOSTACK, G. L. Service positioning through structural change, Journal of Marketing, v. 51, p. 34-43, 1985.

STAMATIS, D. H. Failure Mode and Effect Analysis FMEA from Theory to Execution. Quality Press ASQ, 1995.

ZEMKE, R. Managing Knock Your Socks Off Services Recovery. Nova York: AMACOM, 2000. 